\title{
O ENSINO DE FÍSICA NO CONTEXTO DA DEFICIÊNCIA VISUAL: ANÁLISE DE UMA ATIVIDADE ESTRUTURADA SOBRE UM EVENTO SONORO - POSIÇÃO DE ENCONTRO DE DOIS MÓVEIS
}

\section{The Physics teaching in the visual deficiency context: analysis of an activity concerning to a sonorous event - position of meeting of two bodies}

Eder Pires de Camargo ${ }^{1}$

Dirceu da Silva ${ }^{2}$

\begin{abstract}
Resumo: Aborda-se a análise de uma atividade de ensino de Física elaborada e aplicada a alunos com deficiência visual, parte de uma pesquisa realizada sobre o tema. Sua estrutura fundamentou-se na busca de soluções a um problema aberto (possível colisão entre um carro e um trem), e seu desenvolvimento prático constituiu-se em dois momentos: No primeiro momento, os alunos ouviram a gravação de uma situação problemática que enfocava o movimento de um carro e de um trem; no segundo momento, por meio de um debate, os alunos descreveram observações, apresentaram suas diferentes interpretações para a situação problema, e propuseram soluções para a questão contida na referida situação. Pretende-se que os resultados aqui apresentados contribuam com o ensino de Física de alunos com a citada deficiência.
\end{abstract}

Palavras-chave: ensino de Física. deficiência visual. atividade de ensino. problemas abertos. evento sonoro.

\begin{abstract}
We report here an analysis of a physical teaching activity for blind students, within a research carried out on this subject. Its structure is based on seeking solutions for a unstructured problem (possible collision between a car and a train). Its development consists on two moments: first the students listened to a record of a car and a train in movement; then the students described their observation, showing different interpretations for the same situation and suggested solutions for the problem. We intend that the results presented in this paper can contribute to belp physics teaching for blind students.
\end{abstract}

Key words: Physics teaching. blind students. teaching activity. unstructured problem. sound event.

\footnotetext{
${ }^{1}$ Doutor em Educação pela Universidade Estadual de Campinas, Unicamp, Campinas, SP. E-mail: camargoep@lpnet.com.br Apoio: FAPESP.

${ }^{2}$ Professor Doutor da Faculdade de Educação, Departamento de Metodologia de Ensino, Universidade Estadual de Campinas Unicamp.E-mail:dircen@unicamp.br
} 


\section{Introdução}

É compreensível que estudantes com deficiência visual apresentem dificuldades com a sistemática do ensino de Física, visto que o mesmo fundamenta-se, em boa parte, em referenciais funcionais visuais (Camargo e Silva, 2003a). Apesar de os outros sentidos serem importantes para os indivíduos (Camargo et al. 2001), o da visão parece ser pré-requisito para toda e qualquer atividade que se realize no ambiente escolar. Anotações no caderno, a utilização da lousa por parte do professor para a realização de tarefas como transcrição de textos ou explicações de exercícios, provas escritas, medições, entre outras, sentenciam o aluno com deficiência visual ao fracasso escolar e à não socialização (Mantoan, 2002).

Fatos como estes corroboram a análise da bibliografia especializada sobre a educação da pessoa com deficiência visual, que mostrou que procedimentos de ensino para esses indivíduos são definidos a partir de padrões adotados para os videntes (Masini, 2002). Como o "conhecer" esperado na educação do deficiente visual tem como pressuposto o "ver" (Camargo e Silva 2004), não são levadas em conta pelos professores de Física as diferenças de percepção entre o deficiente visual e o vidente, fato que colabora com a perpetuação de uma prática descontextualizada e mecânica de ensino de Física para alunos com deficiência visual. Se for feita uma breve análise das práticas pedagógicas, da estrutura curricular e escolar, dos livros didáticos, das formas de avaliação, do número de pesquisas destinado a tal tema e das grades curriculares dos cursos de formação de professores de Física não será difícil notar tal fato (Camargo e Silva 2003b).

$\mathrm{Na}$ perspectiva descrita, que tipo de atitude pode ser adotada a fim de construir uma prática de ensino de Física que contemple as necessidades educacionais dos alunos com deficiência visual? Supõe-se que a resposta a tal questionamento encontre-se no rompimento de atitudes e hábitos estabelecidos pelos educadores nas práticas tradicionais de ensino e que constituíram modelos para a elaboração e a condução de atividades de ensino de Física (Camargo e Silva, 2003a).

Pretende-se sugerir alguns direcionamentos para o ensino de Física de alunos com deficiência visual e, para tanto, será apresentada uma atividade que aborda um problema aberto (posição de encontro de dois móveis): a gravação de um evento sonoro que descreve o movimento de um carro e um trem e uma análise da aplicação dessa atividade a um grupo de alunos com deficiência visual. Entende-se, entretanto, que a atividade e o material aqui expostos não fornecem "fórmulas prontas" no que se refere à generalização de tal prática, pois são os contextos de sala de aula que indicarão a seus participantes o "caminho a seguir" (Mantoan, 2002).

\section{Alunos participantes da atividade}

A atividade aqui apresentada faz parte de um conjunto de cinco atividades elaboradas para o ensino do conceito "aceleração" a alunos cegos ou com baixa visão,conjunto que constituiu um curso aplicado a um grupo de nove alunos com deficiência visual freqüentadores da instituição "Lar Escola Santa Luzia para Cegos", localizada na cidade de Bauru. Dos nove alunos que constituíam o número total de participantes do curso completo, cinco parti- 
ciparam da atividade aqui relatada. A formação escolar dos discentes variava de Ensino Fundamental incompleto até Ensino Médio completo, passando por Ensino Fundamental completo e Ensino Médio incompleto. A idade dos alunos variava entre 16 e 35 anos.

\section{Metodologia}

O trabalho aqui exposto caracteriza-se como uma investigação qualitativa orientada por um caráter quase-experimental, a julgar pela análise dos efeitos produzidos devido à aplicação de uma atividade de ensino de Física a um grupo de alunos com deficiência visual não distribuídos aleatoriamente em diferentes condições (Selltiz et al., 1987). Na seqüência, iremos fazer a distinção de um "experimento" de um "quase experimento".

Segundo Selltiz et al. (1987, p. 35), "Experimentos são planejados para responder a questões sobre causas e efeitos. Eles exigem que o experimentador exerça controle sobre o que ocorre e a quem ocorre ... Os experimentadores distribuem por processo de sorteio as pessoas ou outras unidades, tais como classes de alunos, em diferentes condições, aplicam a essas pessoas ou grupos sociais um determinado tratamento, e medem os efeitos desse tratamento".

Não obstante, os quase-experimentos são planejados para responder questões sobre causas e efeitos em situações em que os experimentos não podem ser realizados. Como indicam Selltiz et al. (1987, p. 35 ) "um pesquisador que não possa distribuir por processo de sorteio as pessoas pelas condiçôs, poderá planejar um delineamento quase-experimental para precisar se um determinado tratamento tem um certo efeito".

Os processos de distribuição do sujeito que os quase-experimentos incluem são processos de seleção que naturalmente ocorrem no mundo. Segundo Selltiz et al. (1987, p. 46) "eles possibilitam o estudo dos efeitos que tratamentos possuem sobre aquele segmento da população que também é o mais provável de escolher ou ser escolbido para o tratamento". Como para o estudo do problema educativo aqui apresentado são analisados os efeitos de um tratamento pedagógico em um grupo de alunos com deficiência visual não distribuídos aleatoriamente, a pesquisa exposta se caracteriza como sendo um delineamento quase-experimental.

Embora a abordagem metodológica utilizada se aproxime de um modelo quase-experimental, é a qualidade do retorno fornecido pelos alunos devido ao processo que constituiu a atividade aplicada que configura o aspecto mais importante dos dados coletados (Ludke e André, 1986). Como apontam Morales e Moreno (1993): “os trabalhos qualitativos são marcados pela não manipulação de variáveis, pelo uso de procedimentos não padronizados, tais como: entrevistas não sistematizadas ou coleta de dados em uma determinada realidade, pelo envolvimento do investigador na pesquisa, pelo não controle de variáveis estranhas ou pelo controle mínimo e pela não utilização de estatística".

Como as informações acerca do fenômeno educativo observado surgiram em um contexto dinâmico de relações, a coleta de informações por meio de gravações sonoras e visuais e anotações feitas pelo pesquisador revelou o caráter descritivo dos dados coletados e se mostrou muito útil para sua análise, nitidamente qualitativa, centrada nas qualidades das falas e dos processos que os alunos apresentaram e aos quais foram submetidos, conforme veremos adiante. 


\section{Modelo pedagógico para a elaboração e condução da atividade}

A atividade de ensino de Física aqui apresentada apóia-se em dois componentes práticos: tarefas e debates (Wheatley, 1991), e possui uma estrutura interna que se fundamenta em três elementos: interação com o objeto de estudo, resolução de problemas e confronto de modelos (Peres et al., 1999). Tanto os componentes práticos básicos quanto os elementos de estrutura objetivam proporcionar ao discente com deficiência visual: condições para observar o fenômeno estudado, condições para elaborar estratégias e hipóteses para a resolução dos problemas propostos e condições para confrontar as hipóteses elaboradas ao corpo de conhecimento que se dispõe. Na seqüência, apresenta-se a atividade elaborada.

\subsection{A atividade de ensino de Física: posição de encontro}

Objetivo: apresentar aos alunos um problema aberto, de referencial observacional auditivo, cujas soluções exijam a análise do fenômeno físico envolvido; a formulação de hipóteses e a realização de várias tentativas e aproximações. Observa-se que esta proposta didática (atividade aberta) consiste em modificar os enunciados dos problemas, retirando deles os dados numéricos (Sánchez et al., 1995).

Materiais utilizados: a) rádio para tocar $\mathrm{CD}$ ou fita; b) gravação da seguinte situação problema: um carro se aproxima de uma ferrovia. O motorista nota, pelo som do apito e das rodas do trem, o movimento do mesmo. Conseguirá o motorista do carro frear o veículo para que não haja colisão? Gravou-se primeiro o som do carro se movendo, em seguida, o som do trem apitando e se movendo, depois, novamente o som do carro, outra vez o som do trem apitando e se movendo e, por fim, o som do carro e do trem simultaneamente. Observa-se que a esta gravação foi realizada em um estúdio e faz parte de um CD que contém também as gravações de textos e questões. Este CD é parte dos materiais elaborados para o curso de ensino de Física para alunos com deficiência visual anteriormente mencionado e suas informações encontram-se disponíveis em http://www.fc.unesp.br/pos/ciclos/index.htm (clicar em downloads e depois nos arquivos áudio.mp3. Para ouvir a gravação do evento sonoro, clicar no arquivo audio9.mp3).

Procedimentos: a) apresentar aos alunos a gravação da situação-problema descrita; b) proporcionar aos alunos um momento de reflexão sobre a questão do problema; c) proporcionar um momento para o debate da situação-problema em questão.

\subsection{Definição da categoria para a análise da atividade aplicada}

Com a finalidade de realizar uma análise da atividade enquanto "ambiente de ensino/ aprendizagem" (Wheatley, 1991), definiu-se uma categoria de análise denominada: categoria compreensão (Bardin, 1977). Nessa perspectiva, o entendimento de aprendizagem como um subproduto de um processo educativo fundamentou a elaboração da categoria de análise mencionada. Para Bauersfeld (1988): “A aprendizagem pode ser compreendida como sendo a reconstrução subjetiva de significados por meio da negociação desses significados em interações sociais".

Nesse contexto, a concepção de "local de aprendizagem" bastante aceita e fundamentada na metáfora de "local de trabalho" parece não atender às características de um genuíno ambiente de aprendizagem. De acordo com a concepção que compreende um ambiente de aprendizagem como um "local de trabalho", os alunos, entendidos como os trabalhadores, 
devem sempre executar determinados serviços ou tarefas numa relação de troca de performance por aprovação. Como aponta Doyle (1979): “Alunos são pagos pelo que produzem com elogios e graduação (aprovação)". Opondo-se a tal concepção, Wheatley (1991) afirma que os alunos podem assumir o papel de explorador/inventor, e dessa forma, a sala de aula pode ser mais bem caracterizada como um local de aprendizagem, em vez de "local de trabalho", um local onde os significados são o centro das discussões. Nessa perspectiva, o aprendizado pode ser entendido como um subproduto de um processo de realização intencional de ações de explorar, observar, discutir, propor, reformular, processo realizado nas interações sociais e com o objeto de estudo.

Assim, visando analisar se a estrutura da atividade e o material proporcionaram condições para que os alunos com deficiência visual participassem de um ambiente de aprendizagem, elaborou-se a categoria compreensão, obedecendo-se ao seguinte critério organizacional: primeiro transcreveram-se, na íntegra, as falas dos alunos durante a atividade. Em seguida, as declarações que continham relações de causa e efeito (exemplo: isto ocorre por causa daquilo) foram agrupadas em função de semelhanças conceituais. O conjunto de declarações semelhantes foi generalizado em termos de uma proposição - que também pode ser entendida como a síntese conceitual de várias declarações semelhantes de um ou mais alunos, interpretada como sendo uma hipótese utilizada por um ou mais alunos em suas argumentações. As hipóteses identificadas encontram-se apresentadas no tópico 5.2.

A partir da sistemática descrita, fundamentou-se a referida categoria de análise em elementos que indicam três atitudes (elaborar, compartilhar, questionar) adotadas ou não pelos alunos para a compreensão de um determinado fenômeno. Esses elementos, denominados "elementos de compreensão", encontram-se relacionados na seqüência.

Elementos de compreensão:

I: Elaborou hipóteses: este elemento de compreensão refere-se à atitude de um aluno em elaborar determinada hipótese para explicar determinado problema.

II: Compartilhou hipóteses: este elemento de compreensão refere-se à atitude de um aluno em compartilhar com outros determinada hipótese já elaborada durante a discussão de determinado problema.

III: Questionou hipóteses: este elemento de compreensão refere-se à atitude de um aluno em questionar determinada hipótese elaborada por outro aluno.

As atitudes descritas por meio dos três elementos de compreensão foram denominadas: atitudes de compreensão (Benjamim, 2000). Na seqüência, apresenta-se a análise da atividade.

\section{Análise da aplicação da atividade}

Os alunos participantes da atividade serão identificados pelas letras: A, B, D, G e I. O professor que aplicou as atividades, pesquisador e primeiro autor deste trabalho, tem deficiência visual. A aplicação da atividade levou um tempo aproximado de quarenta minutos, divididos da seguinte maneira: dez minutos para a audição da situação problema e trinta minutos para a discussão por meio de um debate das interpretações acerca da situação e para generalizações e conclusões. Analisamos, na seqüência, os dois momentos da atividade relatada. 


\subsection{Análise do momento de audição da situação-problema}

No início da atividade, o professor ligou o toca CD na situação-problema e a mesma, sem a questão final, foi apresentada aos alunos. Houve a necessidade de se colocar duas vezes a gravação para que os alunos ouvissem com detalhes o evento sonoro. Após a segunda exibição da situação-problema, o professor deixou o toca CD expor a questão que havia sido gravada ao final do evento do carro e do trem e solicitou aos alunos que descrevessem o que tinham acabado de ouvir.

Após tal solicitação, iniciou-se um debate que abordou dois aspectos principais: 1 . descrições de observações do evento sonoro; 2. elaborações de hipóteses para as condições que definem uma possível colisão entre o trem e o carro.

Algumas descrições de eventos dos alunos como: "o carro estava saindo, entrando em movimento", "o carro e o trem já estavam em movimento", "pelo ruído eu acho que não haverá colisão", "a velocidade do trem está muito devagar" indicam que, ao ouvirem a gravação da situação-problema os alunos começaram a imaginar eventos que relacionavam o movimento do carro e do trem. Esse processo de imaginar possíveis eventos nos quais o carro e o trem poderiam colidir ou não foi fundamental para a discussão das variáveis físicas que definem a posição de encontro de dois móveis.

A análise de tal discussão é apresentada na seqüência.

\subsection{Momento de busca de soluções ao problema aberto}

Neste momento, por meio de um debate, os alunos descreveram observações, apresentaram suas diferentes interpretações para a situação-problema e propuseram soluções para a questão nela contida. Um "conjunto conceitual” identificado nas relações entre causa e efeito estabelecidas pelos alunos em suas declarações é explicitado aqui de forma sintética por doze hipóteses. Na seqüência, apresentam-se as hipóteses identificadas e algumas das declarações dos alunos que justificam uma determinada hipótese (ao menos uma declaração de cada aluno que utilizou-se de determinada hipótese). Observa-se que devido ao limite do espaço para a apresentação desse artigo não foi possível a disposição de todas as declarações dos alunos. Destaca-se que as declarações encontram-se dispostas de acordo com uma seqüência cronológica de acontecimento.

\section{Hipóteses utilizadas pelos alunos para explicar o problema aberto: posição de encontro}

Hipótese (1): Se os veículos estão se movendo em trajetórias não paralelas, a não ocorrência de colisão depende da distância entre os veículos.

B: depende da distância que eles estiverem. Se estiverem longe, ele consegue parar, se estiverem perto, não.

Hipótese (2): Se os veículos estão se movendo em trajetórias não paralelas, a não ocorrência de colisão depende da aceleração do carro.

A: O que vai influenciar é a aceleração, o giro do motor do carro está muito forte. 
O ensino de Física no contexto...

Hipótese (3): A ocorrência ou não de colisão depende da direção das trajetórias dos veículos.

A: Uma situação possivel é eles estarem andando paralelos, aí não tem choque nenhum. No início eu pensei em uma situação perpendicular, mas agora eu vejo que pode ter essa outra.

G: Você veja: na gravação, primeiro a gente ouve o som do carro dando partida, depois do trem dando partida, depois dos dois juntos, contudo a gente não sabe se eles estão andando paralelamente ou não.

Hipótese (4): Se os veículos estão se movendo em trajetórias perpendiculares, a não ocorrência de colisão depende da intensidade da velocidade do carro.

A: Se eles estivessem perpendicularmente na velocidade que o carro estava eles batiam.

$B$ : Se o carro estiver em alta velocidade ele não vai conseguir parar!

$D$ : Naquela velocidade do carro, vai bater.

Hipótese (5): Se os veículos estão se movendo em trajetórias perpendiculares, a não ocorrência de colisão depende da intensidade da aceleração do carro e da distância do carro ao trem.

G: Se ele for cruzar com a aceleração que ele estava eu acredito que o carro conseguiria. Iria depender também da distância dele ao trem, se a distância entre eles fosse de uns $20 \mathrm{~m}$, eu acho que ele passa.

Hipótese (6): Se os veículos estão se movendo em trajetórias perpendiculares, a não ocorrência de colisão depende das intensidades das velocidades do carro e do trem.

$D$ : Acho que o carro não pode estar muito devagar, o trem é rápido e se o carro estiver muito devagar o trem pega ele.

Hipótese (7): Se os veículos estão se movendo em trajetórias perpendiculares, a não ocorrência de colisão depende da intensidade da velocidade do carro e da distância que este se encontra do trem.

A: Vai ter que faz̧er uma relação entre distância e velocidade, se você estiver em uma pequena distância você vai ter que estar em uma baixa velocidade, os dois fatores influenciam.

I: Se você estiver em uma pequena distância e baixa velocidade você consegue parar, se a distância for pequena e a velocidade grande você não pára, não vai dar tempo para frear, a desaceleração requer um espaço minimo.

Hipótese (8): Se os veículos estão se movendo em trajetórias perpendiculares, a não ocorrência de colisão depende da intensidade das velocidades dos veículos e da distância que esses veículos estão do ponto de intersecção de suas trajetórias.

$G$ : Tem que analisar a velocidade do trem e tem que analisar a velocidade do carro, a distância que o carro está da linha de cruzar (ponto de encontro) se ele for cruzar, tem que analisar a velocidade do trem e a distância que ele está da linha de cruzada (ponto de encontro).

A: Eu estava pensando aqui sobre a seguinte situação. A gente vai atravessar a rua. Sem a visão, a gente usa o som, a referência sua é som, e até você ter uma noção da distância de segurança para você passar. Quem está vendo a pessoa olha e pronto, consegue dimensionar melhor a distância, a velocidade do veículo... 
para a gente a percepção da velocidade depende se tem mais veículos... já à distância você consegue perceber se está em alta ou baixa velocidade... já o carro silencioso dificulta mais.

Hipótese (9): Se os veículos estão se movendo em trajetórias perpendiculares, a não ocorrência de colisão depende da intensidade do atrito entre os pneus do carro e o asfalto e da distância entre o carro e o trem.

A: Se estivesse chovendo precisaria de um espaço maior para frear, já que diminui o atrito, o atrito com a chuva se torna menor.

Hipótese (10): Se os veículos estão se movendo em trajetórias perpendiculares, a não ocorrência de colisão depende do peso do trem, porque o peso influencia no tempo de frenagem.

B: Voltando ao problema do trem, eu acho que o peso influencia também no fato dele parar ou não, ele não pára fácil, tem que ter uma distância ainda maior, devido ao próprio peso dele.

Hipótese (11): Se os veículos estão se movendo em trajetórias perpendiculares, a não ocorrência de colisão depende da intensidade das velocidades dos veículos, de suas distâncias ao ponto de intersecção de suas trajetórias e da intensidade do atrito entre os pneus do carro e o asfalto e as rodas do trem e os trilhos.

G: A colisão depende da velocidade do trem, da velocidade do carro, da distância que cada um deles estará da linha de encontro e dos atritos entre o carro e o chão e o trem e os trilhos.

Hipótese (12): Se os veículos estão se movendo em trajetórias oblíquas, com o ângulo de intersecção pequeno, a ocorrência ou não de colisão depende da dimensão dos veículos, de suas velocidades e da distância que eles se encontram do ponto de intersecção de suas trajetórias.

A: O trem tem que chegar primeiro, ele é grande, o carro tem chance de chegar primeiro e passar, o carro é pequeno... dependendo da velocidade, é claro, sempre entra a história da velocidade, se o carro chegar primeiro numa velocidade alta, ele passa, contudo o trem, mesmo chegando primeiro numa velocidade alta, o carro pega, o trem é muito maior, o espaço que ele vai ocupar é muito maior.

G: Isso depende muito da noção do motorista, ele que vai ser o responsável por bater ou não. Dessa forma o motorista tem que analisar a distância, a velocidade que o trem vai indo, para que ele possa controlar a velocidade que ele acha que vai dar para passar ou não.

Analisando as doze hipóteses à luz da categoria anteriormente definida, pode-se explicitar as características das atitudes de compreensão utilizadas pelos alunos durante o debate. O quadro (1) apresenta uma relação entre os alunos e os elementos de compreensão. 
O ensino de Física no contexto...

\begin{tabular}{|c|c|c|c|c|c|}
\hline Alunos: & A & B & D & G & $\mathbf{I}$ \\
\hline Hipótese (1) & $\begin{array}{c}\text { Não demonstrou } \\
\text { atitudes }\end{array}$ & Elaborou & $\begin{array}{c}\text { Não demonstrou } \\
\text { atitudes }\end{array}$ & $\begin{array}{c}\text { Não demonstrou } \\
\text { atitudes }\end{array}$ & $\begin{array}{c}\text { Não demonstrou } \\
\text { atitudes }\end{array}$ \\
\hline Hipótese (2) & Elaborou & $\begin{array}{c}\text { Não demonstrou } \\
\text { atitudes }\end{array}$ & $\begin{array}{c}\text { Não demonstrou } \\
\text { atitudes }\end{array}$ & $\begin{array}{c}\text { Não demonstrou } \\
\text { atitudes }\end{array}$ & $\begin{array}{c}\text { Não demonstrou } \\
\text { atitudes }\end{array}$ \\
\hline Hipótese (3) & Elaborou & $\begin{array}{c}\text { Não demonstrou } \\
\text { atitudes }\end{array}$ & $\begin{array}{c}\text { Não demonstrou } \\
\text { atitudes }\end{array}$ & Compartilhou & $\begin{array}{c}\text { Não demonstrou } \\
\text { atitudes }\end{array}$ \\
\hline Hipótese (4) & Elaborou & Compartilhou & Compartilhou & $\begin{array}{c}\text { Não demonstrou } \\
\text { atitudes }\end{array}$ & $\begin{array}{c}\text { Não demonstrou } \\
\text { atitudes }\end{array}$ \\
\hline Hipótese (5) & $\begin{array}{c}\text { Não demonstrou } \\
\text { atitudes }\end{array}$ & $\begin{array}{c}\text { Não demonstrou } \\
\text { atitudes }\end{array}$ & $\begin{array}{c}\text { Não demonstrou } \\
\text { atitudes }\end{array}$ & Elaborou & $\begin{array}{c}\text { Não demonstrou } \\
\text { atitudes }\end{array}$ \\
\hline Hipótese (6) & $\begin{array}{c}\text { Não demonstrou } \\
\text { atitudes }\end{array}$ & $\begin{array}{c}\text { Não demonstrou } \\
\text { atitudes }\end{array}$ & Elaborou & $\begin{array}{c}\text { Não demonstrou } \\
\text { atitudes }\end{array}$ & $\begin{array}{c}\text { Não demonstrou } \\
\text { atitudes }\end{array}$ \\
\hline Hipótese (7) & Elaborou & $\begin{array}{c}\text { Não demonstrou } \\
\text { atitudes }\end{array}$ & $\begin{array}{c}\text { Não demonstrou } \\
\text { atitudes }\end{array}$ & $\begin{array}{c}\text { Não demonstrou } \\
\text { atitudes }\end{array}$ & Compartilhou \\
\hline Hipótese (8) & Compartilhou & $\begin{array}{c}\text { Não demonstrou } \\
\text { atitudes }\end{array}$ & $\begin{array}{c}\text { Não demonstrou } \\
\text { atitudes }\end{array}$ & Elaborou & $\begin{array}{c}\text { Não demonstrou } \\
\text { atitudes }\end{array}$ \\
\hline Hipótese (9) & Elaborou & $\begin{array}{c}\text { Não demonstrou } \\
\text { atitudes }\end{array}$ & $\begin{array}{c}\text { Não demonstrou } \\
\text { atitudes }\end{array}$ & $\begin{array}{c}\text { Não demonstrou } \\
\text { atitudes }\end{array}$ & $\begin{array}{c}\text { Não demonstrou } \\
\text { atitudes }\end{array}$ \\
\hline Hipótese (10) & $\begin{array}{c}\text { Não demonstrou } \\
\text { atitudes }\end{array}$ & Elaborou & $\begin{array}{c}\text { Não demonstrou } \\
\text { atitudes }\end{array}$ & $\begin{array}{c}\text { Não demonstrou } \\
\text { atitudes }\end{array}$ & $\begin{array}{c}\text { Não demonstrou } \\
\text { atitudes }\end{array}$ \\
\hline Hipótese (11) & $\begin{array}{c}\text { Não demonstrou } \\
\text { atitudes }\end{array}$ & $\begin{array}{c}\text { Não demonstrou } \\
\text { atitudes }\end{array}$ & $\begin{array}{c}\text { Não demonstrou } \\
\text { atitudes }\end{array}$ & Elaborou & $\begin{array}{c}\text { Não demonstrou } \\
\text { atitudes }\end{array}$ \\
\hline Hipótese (12) & Elaborou & $\begin{array}{c}\text { Não demonstrou } \\
\text { atitudes }\end{array}$ & $\begin{array}{c}\text { Não demonstrou } \\
\text { atitudes }\end{array}$ & Compartilhou & $\begin{array}{c}\text { Não demonstrou } \\
\text { atitudes }\end{array}$ \\
\hline
\end{tabular}

Quadro 1

Relação entre as hipóteses identificadas e as atitudes definidas na categoria compreensão.

Como mostra o quadro, não ocorreram questionamentos de hipóteses durante a atividade. O que a caracteriza são as constantes elaborações de novas explicações para o problema aberto e o compartilhamento ou não dessas explicações. Dessa forma, interpretou-se que a utilização de hipóteses distintas para explicar o problema da colisão aqui analisado representou a abordagem por parte de alguns alunos a cada explicação sua, de novas variáveis capazes de influenciar a ocorrência ou não de colisão entre o carro e o trem. A abordagem de novas variáveis ocorria a partir do momento em que, gradativamente, os alunos compreendiam o evento sonoro. Dessa forma, no decorrer do processo de compreensão do evento sonoro, algumas variáveis que ainda não haviam sido abordadas eram e outras, que já haviam sido 
abordadas, deixavam de ser. Essa dinâmica de abordar em determinado momento da atividade uma determinada variável e, em outro momento, outra variável determinou as características conceituais das hipóteses identificadas.

Portanto, em relação às variáveis que podem influenciar a não ocorrência de colisão entre o carro e o trem, os alunos destacaram as seguintes: 1. direção das trajetórias, 2. velocidade, 3. aceleração, 4. dimensão dos veículos, 5. distância, 6. atrito, e 7. peso.

A análise da variável: direção das trajetórias do carro e do trem aponta para um desdobramento duplo ao conjunto de soluções do problema aberto, ou seja, a possibilidade de os veículos estarem se movendo de acordo com trajetórias paralelas ou não paralelas (oblíquas ou perpendiculares).

O caso da situação na qual os veículos se movimentam de acordo com trajetórias paralelas representa uma primeira solução à questão da ocorrência ou não de colisão entre o carro e o trem, já que de acordo com a esta situação, carro e trem não podem se encontrar (solução-1). Neste sentido, os alunos A e G, por meio da hipótese 3, apresentaram a solução utilizando-se, para tal, do conceito de paralelo, distinguindo-o do de perpendicular.

Para o caso dos veículos estarem se movendo de acordo com trajetórias não paralelas, como as oblíquas ou as perpendiculares, existe outro desdobramento que enfoca duas soluções para a não ocorrência de colisão entre o carro e o trem. São elas: uma situação na qual um dos veículos passa antes que o outro pelo ponto de intersecção de suas trajetórias (solução-2. Por exemplo: o carro passa antes que o trem - solução apresentada pelos alunos A, D, e G); e uma outra na qual um dos veículos precisa frear, porque o outro encontra-se cruzando o ponto de interseção de suas trajetórias (solução-3. Por exemplo: o carro precisa frear, porque o trem cruza a estrada - solução apresentada pelos alunos A, B, G, e I).

Em relação à solução-2, os alunos $\mathrm{A}, \mathrm{D}, \mathrm{e} \mathrm{G}$ destacaram as seguintes variáveis físicas que podem influenciar a não ocorrência de colisão: intensidade da velocidade dos veículos, aceleração dos veículos, dimensão dos veículos, distância dos veículos ao ponto de interseção de suas trajetórias.

O aluno A, inicialmente por meio das hipóteses 2 e 4, abordou a influência das variáveis: intensidade da aceleração e das velocidades dos veículos para a não ocorrência de colisão. Posteriormente, por meio da hipótese 12 considerou a influência, para a não ocorrência de colisão, das variáveis: dimensão e intensidade da velocidade dos veículos e distância entre eles.

O aluno D, por meio das hipóteses 4 e 6 (principalmente a 6), abordou a influência da variável: intensidade das velocidades dos veículos para a não ocorrência de colisão, sem abordar as variáveis: aceleração e distância entre eles.

O aluno G, por sua vez, abordou inicialmente, por meio da hipótese 5, a influência das variáveis: aceleração do carro e distância do carro ao trem, em uma possível colisão entre esses veículos. Posteriormente, utilizando-se da hipótese 12, abordou a influência das variáveis: dimensão e intensidade das velocidades dos veículos e distância dos veículos ao ponto de interseção de suas trajetórias.

Note-se que as condições abordadas pelos alunos A, D e G enfocaram variáveis e relações entre variáveis físicas relevantes e determinantes para que um carro consiga cruzar a frente de um trem: o ponto de interseção de suas trajetórias. Contudo, em relação a essas condições, cabe a seguinte análise: 
Para determinar se um carro movendo-se em uma trajetória não paralela à de um trem cruzará o ponto de interseção de suas trajetórias sem ser atingido é fundamental o conhecimento da distância que esses veículos encontram-se do ponto de interseção de suas trajetórias e o tempo que eles levarão para chegar e passar por esse ponto, o que torna fundamental o conhecimento da dimensão desses veículos. Entretanto, a determinação da variável tempo, requer o conhecimento das características dos movimentos do carro e do trem, ou seja, se eles se movem de acordo com um movimento acelerado ou com um movimento constante. Se eles se movem de acordo com um movimento acelerado, é fundamental para a determinação da variável tempo o conhecimento das velocidades iniciais, das características das acelerações desses veículos (constantes ou não) e de fatores influenciadores para a aceleração, como o atrito. Se eles se movem de acordo com um movimento constante, é fundamental para a determinação da variável tempo o conhecimento das intensidades das velocidades do carro e do trem.

Neste sentido, observa-se que os alunos A e G apresentaram condições para a solução 2 mais bem elaboradas do que o aluno $\mathrm{D}$, pois articularam relações entre: distância, dimensão dos veículos, aceleração e velocidade, fundamentais para determinar o tempo mínimo necessário para que o carro passasse à frente do trem sem ser atingido por ele, enquanto o aluno $\mathrm{D}$ articulou as relações entre as velocidades dos veículos, relações também necessárias para a referida determinação.

Em relação à solução-3, os alunos A, B, G e I destacaram as seguintes variáveis: intensidade da velocidade dos veículos, aceleração dos veículos, distância dos veículos ao ponto de interseção de suas trajetórias, dimensão dos veículos, intensidade dos atritos entre os pneus do carro e o asfalto, e das rodas do trem e os trilhos, peso do trem.

O aluno A destacou as seguintes variáveis, que podem influenciar a não ocorrência de colisão entre o carro e o trem: velocidade do carro e distância entre o carro e o trem (hipótese 7); intensidade das velocidades dos veículos e distância que esses veículos estão do ponto de interseção de suas trajetórias (hipótese 8); intensidade do atrito entre os pneus do carro e o asfalto e distância do carro ao trem (hipótese 9); e dimensão e velocidade dos veículos, e distância que esses veículos se encontram do ponto de interseção de suas trajetórias (hipótese 12).

O aluno B, por meio da hipótese 1, abordou a variável: distância entre os veículos. Por meio da hipótese 4 abordou a variável intensidade da velocidade do carro e, por meio da hipótese 10, a variável: peso do trem, como fatores influenciadores para a não ocorrência de colisão entre o carro e o trem.

O aluno G, por sua vez, observou as seguintes variáveis como fatores influenciadores para a não ocorrência de colisão entre o carro e o trem: intensidade das velocidades dos veículos e distância que esses veículos se encontram do ponto de interseção de suas trajetórias (hipótese 8); intensidade das velocidades dos veículos, distância desses veículos ao ponto de interseção de suas trajetórias e intensidade do atrito entre os pneus do carro e o asfalto e as rodas do trem e os trilhos (hipótese 11); dimensão e intensidade das velocidades dos veículos e distância que esses veículos se encontram do ponto de interseção de suas trajetórias (hipótese 12).

O aluno I abordou, por meio da hipótese 7, a influência das variáveis: intensidade da velocidade do carro e distância do carro ao trem, em uma possível colisão entre esses veículos. 
Note que as condições abordadas pelos alunos A, B, G e I enfocaram variáveis e relações entre variáveis físicas relevantes e determinantes para que um carro consiga frear e parar antes do ponto de interseção de sua trajetória com a do trem e, dessa forma, não ser atingido por ele. Contudo, em relação a essas condições, cabe a seguinte análise:

Para determinar se veículos movendo-se de acordo com trajetórias não paralelas conseguirão frear e parar antes do ponto de interseção de suas trajetórias também é fundamental o conhecimento da distância que esses veículos encontram-se do referido ponto e o tempo que eles levarão para chegar e passar por esse ponto, o que torna indispensável o conhecimento da dimensão desses veículos. Entretanto, a determinação da variável tempo requer o conhecimento das características dos movimentos do carro e do trem. Fechando um pouco o problema, e considerando que o carro deva parar para que não haja colisão, é fundamental o conhecimento da intensidade de sua velocidade inicial, das características de sua desaceleração (se é constante ou não) e das características do movimento do trem, ou seja, se é um movimento acelerado (com aceleração constante ou não) ou de velocidade constante. Se o movimento do trem for acelerado, é indispensável conhecer o valor de sua velocidade inicial. Além das grandezas consideradas, o atrito também deve ser levado em conta, já que influencia nas condições de aceleração dos veículos.

De acordo com o que foi discutido, os alunos G e A apresentaram, nessa seqüência, condições mais bem elaboradas em relação às condições dos alunos I e D para a solução 3, pois utilizaram-se e articularam relações entre as variáveis: distância, dimensão dos veículos, intensidade das velocidades e atrito, relações fundamentais para a determinação do tempo máximo de frenagem do carro para que não haja colisão. $\mathrm{O}$ aluno I articulou as relações entre intensidade da velocidade do carro e distância deste ao trem para determinar o tempo máximo de frenagem e o aluno B utilizou-se das mesmas relações, além de considerar a influência do "peso" do trem para o tempo de frenagem do mesmo. Contudo, o "peso" de um objeto - ou, mais especificamente, sua massa, não influencia em seu tempo de frenagem. Dessa forma, a consideração dessa variável por parte do aluno B pode representar efeito de suas concepções espontâneas sobre a relação: massa x tempo.

Em síntese, os alunos apresentaram três soluções para a não colisão entre o carro e o trem. São elas: solução 1 . carro e trem movendo-se em trajetórias paralelas; solução 2 . carro e trem movendo-se em trajetórias não paralelas, sendo que o carro passa antes que o trem pelo ponto de interseção de suas trajetórias; solução 3. carro e trem movendo-se em trajetórias não paralelas, sendo que um dos veículos freia e pára antes do ponto de interseção de suas trajetórias. As variáveis apresentadas pelos alunos que dentro das soluções podem influenciar a não ocorrência de colisão entre o carro e o trem foram as seguintes: direção das trajetórias dos veículos, distância, dimensão dos veículos, velocidade, aceleração, atrito e peso.

A atividade relatada foi capaz de motivar os alunos e proporcionar-lhes condições para que: 1. observassem por meio do referencial auditivo um evento sonoro; 2. propusessem e discutissem diferentes soluções possíveis para um problema aberto; 3. utilizassem e articulassem grandezas físicas; 4. apresentassem problemas não planejados para discussão; e 5. elaborassem e compartilhassem hipóteses durante as discussões estabelecidas. 


\section{Conclusão}

Apresentou-se a análise da aplicação de uma atividade de ensino de Física desenvolvida para alunos com deficiência visual. Como descrito, a atividade abordou o problema aberto de uma possível colisão entre um carro e um trem. Conclui-se que ela proporcionou aos alunos condições para a realização de um estudo qualitativo da situação-problema e, por terem suas idéias valorizadas, os discentes apresentaram hipóteses para explicar uma possível colisão entre o carro e o trem, representadas por três soluções que articulavam variáveis físicas na determinação ou não da colisão.

O CD desenvolvido para essa atividade mostrou-se eficaz para a realização de observações não visuais, o que foi de fundamental importância para a contextualização do problema discutido e para a motivação dos alunos. Nesta perspectiva, tanto a atividade quanto o material gravado atingiram seus objetivos, ou seja: motivar os alunos para a observação e para o estudo do problema da posição de encontro de dois móveis.

Observa-se que o problema aberto mostrou-se muito eficaz em produzir hipóteses acerca dos fatores que definem a posição de encontro de dois veículos, pois possibilitou a abordagem de uma grande quantidade de variáveis. Entretanto, sugere-se que um professor que esteja trabalhando problemas abertos com alunos com deficiência visual, de maneira gradativa, vá ao mesmo tempo valorizando as soluções dos alunos e fechando o problema ou conduzindo o mesmo de acordo com seus interesses. Se ele não quiser, por exemplo, limitar o problema em função de valores numéricos, poderá mantê-lo aberto e explorar as diferentes soluções. Por outro lado, se o professor decidir abordar um problema mais fechado, poderá atribuir valores numéricos às grandezas envolvidas e já discutidas no problema. Neste sentido, talvez uma atividade de ensino de Física para alunos com deficiência visual a ser elaborada seja a de trabalhar equações físicas para estudar o problema da posição de encontro. Contudo, entende-se que a atividade deveria suceder ou ser uma conseqüência de atividades abertas como a aqui apresentada.

Como sugestão, a elaboração de uma atividade para estudar o problema da posição de encontro com alunos com deficiência visual deveria obedecer ao critério organizacional de se tratar inicialmente o caso geral (por meio de problemas abertos) e, posteriormente, o caso específico (com a introdução de valores numéricos às grandezas envolvidas). Assim, na hipótese de o professor propor um problema numérico, talvez exista a possibilidade de se trabalhar com mais detalhes as características dos movimentos do carro e do trem, ou seja, se eles iriam se mover com aceleração constante ou não, velocidade constante ou não... Por outro lado, por meio de um problema aberto muitas variáveis físicas que podem interferir no fenômeno da aceleração podem ser trabalhadas, já que a abordagem de situações imprevistas poderia ficar prejudicada em um problema mais fechado.

Finalizando, conclui-se, da experiência educacional aqui apresentada, que as situações de ensino de Física a alunos com deficiência visual necessitam estar organizadas de maneira que o discente use ao máximo todas as suas possibilidades (táteis, olfativas, auditivas, sinestésicas) e fale sobre sua experiência perceptiva. A postura do docente perante seu aluno com deficiência visual deve ser aquela em que o vidente se posiciona frente ao deficiente visual, ouvindo-o (acompanhando o que ele faz nas diferentes situações) e contribuindo no que for possível para que ele encontre seus próprios meios de agir e superar seus obstáculos. 
Camargo, E. P.; Silva, D.

Como aponta Masine (2002), penetrar no mundo percebido pelo deficiente visual é tão difícil quanto fazê-lo perceber o mundo como o vidente o faz, mas é condição necessária para o ensino de conteúdos de Física a esses indivíduos (Camargo e Silva 2004).

\section{Referências}

BARDIN, L. Análise de conteúdo. Lisboa: Edições 70, 1977. 225p.

BAUERSFELD, H. Interaction, construction, and knowledge: alternative perspectives for mathematics education. In: GROUWS, D.; COONEY, T. (Eds.). Perspectives on research on effective mathematics teaching. Reston, VA: National Council of Teachers of mathematics, 1988.

BENJAMIN, A. A. Análise do uso de um texto paradidático sobre energia e meio ambiente. Bauru. 2000. 184p. Dissertação (Mestrado em Educação para a Ciência) - Faculdade de Ciências, Campus de Bauru, Universidade Estadual Paulista "Júlio de Mesquita Filho".

CAMARGO, E. P.; SILVA, D. Atividade de ensino de física para alunos com deficiência visual: vivência do Atrito: Observação e Contextualização do Fenômeno. In: CONGRESSO INTERNACIONAL DE EDUCAÇÃO E DESENVOLVIMENTO HUMANO, 1., 2004, Maringá. Anais... Maringá: Universidade Estadual de Maringá , 2004.

O ensino de Física, os alunos com deficiência visual e os parâmetros curriculares nacionais. In: SIMPÓSIO EM FILOSOFIA E CIÊNCIA, TRABALHO E CONHECIMENTO: DESAFIOS E RESPONSABILIDADES DA CIÊNCIA, 5., 2003, Marília. Atas... Marília, 2003.

Trabalhando o conceito de aceleração com alunos com deficiência visual: um estudo de caso. In: SIMPÓSIO NACIONAL DE ENSINO DE FÍSICA, 15., 2003, Curitiba. Atas... Paraná, 2003, p. 101.

CAMARGO E. P.; SCALVI L. V. A.; BRAGA T. M. S. O ensino de Física e os portadores de deficiência visual: aspectos observacionais não-visuais de questões ligadas ao repouso e ao movimento dos objetos. In: NARDI, R. (Org). Educação em Ciências: da pesquisa à prática docente. São Paulo: Escrituras, 2001. p. 117-133.

DOYLE, W. Classroom tasks and students' abilities. In: PETERSO, P.; WALBERG, H. (Eds.). Research on teaching: concepts, findings, and implications. Berkeley: Mc Cutchan, 1979. p. 183-209. 
O ensino de Física no contexto...

LUDKE, M.; ANDRÉ, M. E. D. A. Métodos de coletas de dados: observação, entrevista e análise documental: In: Pesquisa em Educação: abordagens qualitativas. São Paulo: EPU, 1986. p. $25-44$.

MANTOAN, M. T. E. Ensinando a turma toda as diferenças na escola: Pátio. Revista Pedagógica, n. 20, p. $18-23$, fev./abr. 2002.

MASINI, E. F. S. A educação de pessoas com deficiências sensoriais: algumas considerações. In: Do sentido, pelos sentidos, para o sentido: o sentido das pessoas com deficiências sensoriais. Editora Vetor, 2002.

MORALES, M.; MORENO, M. Problema en el uso de los terminos cualitativo/cuantitativo en la investigación educativa. Investigación en la escuela, v. 21, p. 149-157, 1993.

PÉREZ, D. G.; ALÍS, J. C.; DUMAS-CARRÉ, A.; MAS, C. F.; GALLEGO, R.; DUCH, A. G.; GONZÁLEZ, E.; GUISASOLA, J.; MARTÍNEZ-TORREGROSSA, J.; CARVALHO, A. M. P.; SALINAS, J.; TRICÁRIO, H.; VALDÉS, P. ¿Puede hablarse de consenso constructivista en la educación científica? Enseñanza de la Ciencia, v. 18, n. 1, 1999.

SELLTIZ, C.; WRIGHTSMAN, L. S.; COOK, S. W. Métodos de pesquisa nas relações sociais. 2. ed., v. 1. São Paulo: EPU, 1977.

SANCHEZ, M. A.; PEREZ, D. G.; TORREGROSA, J. M. Actividades de evaluacion coherentes con una propuesta de enseñanza de la fisica y la quimica como investigacion: actividades de autorregulación e interregulación. Revista de la Ensenñanza de la Física, v. 8, n. 2, p. 5-20, 1995.

WHEATLEY, G. H. Constructivist perspectives on science and mathematics learning. Science Education, v. 75, n. 1, p. 9-2, 1991.

Artigo recebido em dezembro de 2005 e aceito em julho de 2006. 